\title{
Cancer risk following organ transplantation: a nationwide cohort study in Sweden
}

\author{
J Adami",', H Gäbel'2, B Lindelöf', K Ekström', B Rydh', B Glimelius 4,5, A Ekbom', H-O Adami' and F Granath' \\ 'Department of Medical Epidemiology and Biostatistics, Karolinska Institutet, SE-I 7177 Stockholm, Sweden; ${ }^{2}$ The Transplant Unit, National Board of \\ Health and Welfare, SE-I 0630 Stockholm, Sweden; ${ }^{3}$ Department of Dermatology, Karolinska Hospital, SE-I 71 76 Stockholm, Sweden; ${ }^{4}$ Department of \\ Oncology, Radiology and Clinical Immunology, University Hospital, SE-75I 85 Uppsala; ${ }^{5}$ Radiumhemmet, Karolinska Hospital, SE-I 7 I 76 Stockholm, \\ Sweden
}

\begin{abstract}
A substantial excess risk of lymphomas and nonmelanoma skin cancer has been demonstrated following organ transplantation. Large sample size and long follow-up time may, however, allow more accurate risk estimates and detailed understanding of long-term cancer risk. The objective of the study was to assess the risk of cancer following organ transplantation. A nationwide cohort study comprising 5931 patients who underwent transplantation of kidney, liver or other organs during 1970-1997 in Sweden was conducted. Complete follow-up was accomplished through linkage to nationwide databases. We used comparisons with the entire Swedish population to calculate standardised incidence ratios (SIRs), and Poisson regression for multivariate internal analyses of relative risks (RRs) with 95\% confidence intervals (CI). Overall, we observed 692 incident first cancers vs 17I expected (SIR 4.0; 95\% Cl 3.7-4.4). We confirmed marked excesses of nonmelanoma skin cancer (SIR 56.2; 95\% Cl 49.8-63.2), lip cancer (SIR 53.3; 95\% Cl 38.0-72.5) and of non-Hodgkin's lymphoma (NHL) (SIR 6.0; 95\% Cl 4.4-8.0). Compared with patients who underwent kidney transplantation, those who received other organs were at substantially higher risk of $\mathrm{NHL}$ (RR 8.4; 95\% Cl 4.3-16). Besides, we found, significantly, about 20-fold excess risk of cancer of the vulva and vagina, I0-fold of anal cancer, and five-fold of oral cavity and kidney cancer, as well as two- to four-fold excesses of cancer in the oesophagus, stomach, large bowel, urinary bladder, lung and thyroid gland. In conclusion, organ transplantation entails a persistent, about four-fold increased overall cancer risk. The complex pattern of excess risk at many sites challenges current understanding of oncogenic infections that might become activated by immunologic alterations.
\end{abstract}

British Journal of Cancer (2003) 89, I22I-1227. doi:I0.1038/sj.bjc.660I219 www.bjcancer.com

(c) 2003 Cancer Research UK

Keywords: organ transplantation; epidemiology; cohort study

Previous epidemiological studies have reported an overall threefive-fold increased risk of neoplasias among transplanted patients compared with the general population (Hoover and Fraumeni, 1973; Kinlen et al, 1979; Birkeland et al, 1995, 2000; Hoshida et al, 1997; Kyllonen et al, 2000; Lindelof et al, 2000). The malignancies most consistently associated with organ transplantation include nonmelanoma skin cancer and lymphoproliferative malignancies (Hoover and Fraumeni, 1973; Kinlen et al, 1979; Blohme and Brynger, 1985; Barr et al, 1989; Kinlen, 1992; Opelz and Henderson, 1993; Birkeland et al, 1995, 2000; Bouwes Bavinck et al, 1997; Hoshida et al, 1997; Kyllonen et al, 2000; Lindelof et al, 2000; Penn, 2000). There is limited and somewhat conflicting evidence of any relationship between other cancers and transplantation (Hoover and Fraumeni, 1973; Porreco et al, 1975; Kinlen et al, 1979; Blohme and Brynger, 1985; Barr et al, 1989; Kinlen, 1992; Opelz and Henderson, 1993; Penn, 1993, 2000; Birkeland et al, 1995, 2000; Bouwes Bavinck et al, 1997; Hoshida et al, 1997; Kyllonen et al, 2000; Lindelof et al, 2000). Several previous studies were hampered by small size and short follow-up times resulting in lack of

\footnotetext{
*Correspondence: Dr J Adami, Department of Medical Epidemiology, Karolinska Institutet, Box 28I, SE-I7I 77 Stockholm, Sweden;

E-mail: johanna.adami@mep.ki.se

Received 20 February 2003; revised 2 July 2003; accepted 2 July 2003
}

statistical precision. Moreover, only few studies (Hoover and Fraumeni, 1973; Kinlen et al, 1979; Birkeland et al, 1995, 2000; Hoshida et al, 1997; Kyllonen et al, 2000) were population based, allowing valid comparisons with the reference population from which the cancer cases arose. In an attempt to further qualify and quantify the risk of cancer following organ replacement, we expanded a previously analysed (Lindelof et al, 2000) large population-based nationwide cohort study in Sweden with virtually complete follow-up.

\section{MATERIAL AND METHODS}

This study was approved by the Ethical Committee at the Karolinska Institutet, Stockholm, Sweden.

\section{The Swedish in-patient register}

Since 1965, the National Board of Health and Welfare has collected data on individual hospital discharges in the in-patient register, described in detail elsewhere (Nyren et al, 1995). The proportion of the Swedish population covered by this register increased from $60 \%$ in 1969 to $85 \%$ in 1983 , and $100 \%$ from 1987 onwards. Each record contains up to eight discharge diagnoses, coded according to the seventh revision of the International Classification of 
Diseases (ICD-7) 1964-1968, the eighth revision (ICD-8) 19691986 and the ninth revision (ICD-9) thereafter. Furthermore, each record contains up to 10 surgical codes, assigned according to the Swedish Classification of Operations and Major Procedures (Nyren et al, 1995).

The individually unique 10 digit national registration number ascribed to every Swedish citizen ensures accurate identification and follow-up of each patient who has undergone organ transplantation. When the in-patient register was evaluated for validity and completeness, codes for surgical procedures were correct for $98 \%$ of the records (Nilsson et al, 1994).

\section{The Swedish Cancer Registry}

The Swedish Cancer Registry, started in 1958, receives reports of all incident malignant tumours diagnosed in Sweden, but does not take into account information from death certificates (The Swedish Cancer Registry, 2001). Reporting by both diagnosing physicians and pathologists is mandatory by law, resulting in registration of more than $98 \%$ of all incident tumours, with histological verification of $97 \%$ of the tumours. During the years of followup for this study, the ICD-7 was used to classify all incident cancers as specified in Table 2. As chronic lymphocytic leukaemias (ICD-7: 204.1) belong to the non-Hodgkin's lymphomas (Harris et al, 1994), they were included in this group. The nonmelanoma skin cancer group (ICD-7: 191) does not include basal cell carcinomas since these are not reported to the Swedish Cancer Register.

\section{Definition of study cohort}

In Sweden, a few kidney transplantations were accomplished during the late $1960 \mathrm{~s}$ but this activity first became routine during the 1970s (Figure 1). Organ transplantation is only performed at four specialised centres belonging to public university hospitals; as a result, private in-patient treatment is nonexistent. Therefore, hospital-provided medical services associated with organ transplantation are, in effect, population based. From the in-patient register, we selected all 6457 patients who were hospitalised during 1970-1997 for organ transplantation. Two of four centres (Stockholm and Gothenburg) were not covered by the in-patient registry until 1972 and onwards. Some 50 organ transplantations performed at these centres during 1970 and 1971 were therefore not included in our study cohort (Lindelof et al, 2000) unless they were retransplanted after 1971; if so, the date of retransplantation would be erroneously recorded as the first transplantation. The surgical codes used for selection were the following: 6070 (kidney), 5530, 5531 (pancreas), 5200, 5202 (liver), 3590 (lung) and 3085 (heart).

The date of first recorded transplantation marked entry into the cohort. We excluded patients with a previous history of any cancer $(n=77)$ or cancers reported within 30 days after transplantation $(n=179)$, patients with unknown transplantation codes $(n=258)$ or mismatching transplantation dates $(n=12)$. Following these exclusions, a total of 5931 eligible patients treated with transplantation of the kidney, liver, heart, lung, pancreas or a combination of solid organs were thus available for follow-up and further analyses.

\section{Follow-up}

The in-patient register was used only to characterise patients with organ transplantation at entry into the cohort. Linkage with the Death register, Register of Population changes and Swedish Cancer Register, respectively, provided information on vital status, emigration and cancer incidence in the cohort during follow-up. We had no reliable information about explantation of organs after the index operation. The follow-up began 30 days after transplan-

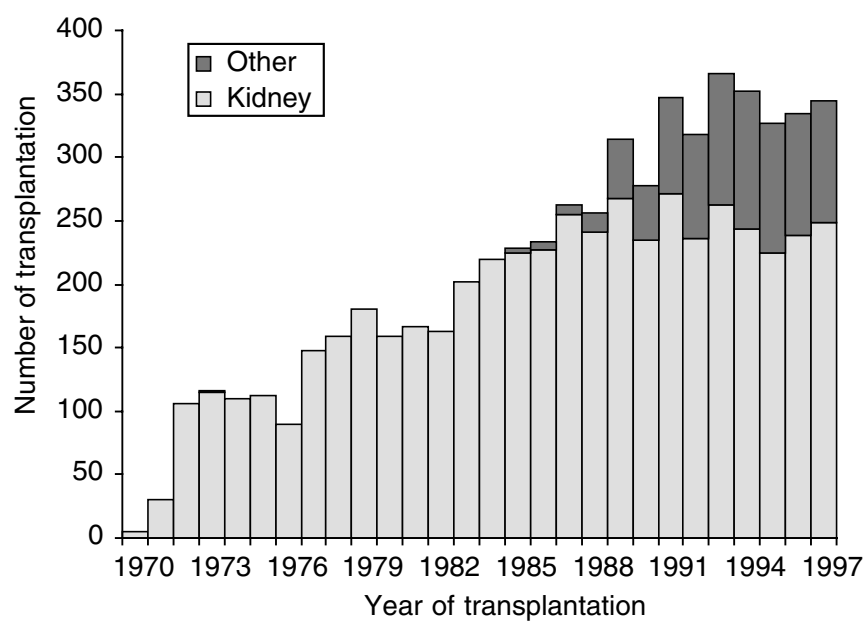

Figure I Total number of patients undergoing organ transplantation in Sweden per year during 1970-1997. The dark bars show number of transplantations other than kidney.

tation, in order to exclude prevalent cancers, and continued until diagnosis of cancer, date of death or end of follow-up on 31 December, 1997, whichever occurred first.

\section{Analyses}

Expected numbers of cancers were calculated by multiplying the age, gender and calendar-year-specific risk time by the corresponding cancer incidence rates of the general Swedish population. The standardised incidence ratio (SIR), the ratio of the observed to the expected number of incident cancers, was used to estimate the relative risk (RR) of tumours for different categories. We only counted first cancers (since completeness of reporting second primary malignancies has not been validated), and disregarded prevalent cancers detected incidentally at autopsy (because bias would be introduced if autopsy rates differ between patients with organ transplantation and the general population), both in the cohort and in the expected rates. Confidence intervals of standardised incidence ratio were calculated assuming that the observed number of events followed a Poisson distribution (Breslow and Day, 1987). The observed number of all cancers, nonmelanoma skin cancers, lip cancers and non-Hodgkin's lymphomas (NHLs) - stratified according to all the combinations of the variables given in Table 4 were analysed by Poisson regression with the logarithm of the expected number as an offset term. These analyses yield an assessment of the independent effect of each variable adjusting for potential confounding factors of the others. These analyses were used to assess the statistical significance of each variable, and the results are presented as RRs representing standardised incidence ratios.

\section{RESULTS}

\section{Overall findings}

Selected characteristics of the cohort members are shown in Table 1. A total of 3592 male and 2339 female patients were studied. The vast majority received a kidney transplant $(84.3 \%)$. The median age at transplantation was 46 years and the mean follow-up time was 6.8 years, yielding a total of 40360 person-years of follow-up. Figure 1 illustrates the number of patients included per calendar year, showing a successive increase from approximately 100 transplantations per year in the early 1970s to 300 during the 1990s. Through 1984, the cohort only included patients 
Table I Characteristics of 5931 patients who underwent organ transplantation in Sweden 1970-1997

\begin{tabular}{|c|c|c|c|}
\hline Characteristics & $\begin{array}{l}\text { No. of } \\
\text { subjects }\end{array}$ & Proportion & $\begin{array}{c}\text { Person- } \\
\text { years }\end{array}$ \\
\hline Total & 5931 & 100 & 40360 \\
\hline \multicolumn{4}{|l|}{ Transplanted organ } \\
\hline Kidney & 5004 & 84.3 & 36963 \\
\hline Liver & 394 & 6.6 & 1254 \\
\hline Heart & 236 & 3.9 & 960 \\
\hline Lung & 117 & 1.9 & 324 \\
\hline Pancreas & 26 & 0.4 & 98 \\
\hline Combination of organs & 154 & 2.5 & 759 \\
\hline Age-distribution at entry & No. of subjects & & Proportion (\%) \\
\hline$<40$ & 2262 & & 38 \\
\hline $40-49$ & 412 & & 24 \\
\hline $50-59$ & | 487 & & 25 \\
\hline $60+$ & 770 & & 13 \\
\hline \multicolumn{4}{|l|}{ Gender } \\
\hline Males & 3592 & & 61 \\
\hline \multirow[t]{2}{*}{ Females } & 2339 & & 39 \\
\hline & Years & & Range \\
\hline Median age at transplantation & 46 & & $0-84$ \\
\hline Mean follow-up time & 6.8 & & $0-26.8$ \\
\hline
\end{tabular}

receiving kidney transplants, whereas after that an increasing number of other organ transplantations were performed and corresponded to about $30 \%$ of all transplants from the early $1990 \mathrm{~s}$.

Table 2 summarises the SIRs for different cancer sites following organ transplantation. Overall, we observed 692 primary cancers (counting first cancer at each site) vs 171 expected, yielding an SIR of $4.0(95 \% \mathrm{CI}=3.7-4.4)$. Table 3 summarises the SIRs for selected cancers with adequate numbers for analysis stratified by type of transplantation. The overall cancer risk does not differ significantly between the groups. The risk of developing lip- and nonmelanoma skin cancer is notably higher among renal transplant patients, although this comparison is most likely confounded by the shorter follow-up time among nonrenal transplant patients. Multivariate analysis (Table 4) indicated that this excess risk remained stable during the entire follow-up period. The excess risk decreased monentously with increasing age and was 2.5-fold higher among patients aged less than 40 compared with those who were 60 years or older at transplantation. Relative Risk was also significantly higher in men than in women. Lastly, we compared the overall excess cancer risk in relation to the type of transplanted organ and found slightly lower overall risk following kidney transplantation compared to transplantation of other organ(s) (Table 4).The cumulative risk of developing any malignancy was $13.6 \%(95 \% \mathrm{CI}=12.4-15.0) 10$ years, and $31.8 \%$ $(95 \% \mathrm{CI}=28.4-35.3) 20$ years after transplantation (Figure 2).

\section{Head and neck region and gastrointestinal tract}

We found a significant almost six-fold excess risk for cancer of the oral cavity based on 11 observed cases (Table 2). The excess was highest for cancer of the tongue (SIR $=10.7 ; 95 \%$ CI $4.3-22.1$ ). Based on small numbers, we also found consistent, albeit statistically nonsignificant about three-fold elevated risks for cancer of other parts of the oral cavity and the head and neck region such as salivary glands, floor of the mouth, pharynx and larynx.

A three-fold, significantly increased risk was revealed for oesophageal cancer based on five cases (Table 2). Two of these patients were diagnosed with adenocarcinoma and three with
Table 2 Cancer risk following organ transplantation in Sweden, 19701997

\begin{tabular}{|c|c|c|c|}
\hline Cancer site (ICD-7) & $\begin{array}{l}\text { Observed } \\
\text { no. cases }\end{array}$ & SIR & $95 \% \mathrm{Cl}$ \\
\hline Overall & 692 & 4.0 & $3.7-4.4$ \\
\hline Lip (140) & 40 & 53.3 & $38.0-72.5$ \\
\hline Oral cavity $(|4|-\mid 44)$ & 11 & 5.5 & $2.7-9.8$ \\
\hline Pharynx (145-146) & 3 & 3.1 & $0.6-9.1$ \\
\hline Oesophagus (150) & 5 & 3.2 & $1.1-7.5$ \\
\hline Stomach (15I) & 12 & 2.3 & $1.2-4.1$ \\
\hline Small intestine (152) & I & 1.1 & $0.0-6.2$ \\
\hline Colon (I53) & 25 & 2.3 & $1.5-3.4$ \\
\hline Rectal $(|54.0+| 54.1)$ & 14 & 1.9 & $1.0-3.2$ \\
\hline Adenocarcinomas & 9 & 1.4 & $0.7-2.6$ \\
\hline Squamous cell carcinoma & 4 & 10.2 & $2.8-26.0$ \\
\hline Liver, primary (I55) & 4 & 1.1 & $0.3-2.8$ \\
\hline Pancreas (I57) & 4 & 0.9 & $0.3-2.3$ \\
\hline Nose, middle ear (160) & 2 & 6.8 & $0.8-24.5$ \\
\hline Larynx (|6I) & 3 & 2.5 & $0.5-7.3$ \\
\hline Lung (162) & 24 & 1.7 & $1.1-2.5$ \\
\hline Mediastinum (164) & I & 42.9 & $1.1-239$ \\
\hline Breast $(170)$ & 24 & 1.0 & $0.6-1.5$ \\
\hline Cervix uteri (I7I) & 5 & 2.0 & $0.7-4.7$ \\
\hline Cervix in situ & 52 & 1.3 & $1.0-1.8$ \\
\hline Ovary (I75) & 9 & 2.0 & $0.9-3.8$ \\
\hline Vulva and vagina (176) & 11 & 20.9 & $10.4-37.4$ \\
\hline Vulva & 9 & 26.2 & $12.0-49.8$ \\
\hline Vagina & 2 & 16.4 & $2.0-59.3$ \\
\hline Prostate (177) & 20 & 1.1 & $0.7-1.7$ \\
\hline Testis (178) & 3 & 2.3 & $0.5-6.6$ \\
\hline Kidney $(180)$ & 28 & 4.9 & $3.3-7.1$ \\
\hline Bladder $(18 \mid)$ & 20 & 2.3 & $1.4-3.6$ \\
\hline Malignant melanoma (190) & 14 & 1.8 & $1.0-3.0$ \\
\hline Nonmelanoma skin cancer (191) & 278 & 56.2 & $49.8-63.2$ \\
\hline Eye (192) & । & 2.0 & $0.0-10.9$ \\
\hline Brain (193) & 7 & 1.0 & $0.4-2.1$ \\
\hline Thyroid (194) & 6 & 3.8 & $1.4-8.2$ \\
\hline Connective tissue (197) & 3 & 2.3 & $0.5-6.7$ \\
\hline Non-Hodgkin's lymphoma $(200+202+204.1)$ & 45 & 6.0 & $4.4-8.0$ \\
\hline Hodgkin's disease (20I) & 2 & 2.2 & $0.3-8.1$ \\
\hline Multiple myeloma (203) & 6 & 2.7 & $1.0-5.9$ \\
\hline Lymphocytic leukaemia (204) & 3 & 1.8 & $0.4-5.1$ \\
\hline Myeloic leukaemia (205) & 5 & 2.9 & $0.9-6.7$ \\
\hline
\end{tabular}

Observed number of cases, SIR (SIR) and $95 \%$ confidence intervals (Cl) by cancer site and type.

squamous cell carcinomas. Moreover, risk for gastric cancer was increased two-fold.

Although based on small numbers, the risk seemed to be higher for cancer diagnosed in the proximal part of the stomach $(\mathrm{SIR}=4.4,95 \% \mathrm{CI}=1.2-11.3)$ than in the distal parts $(\mathrm{SIR}=2.2$, $95 \% \mathrm{CI}=0.6-5.6)$.

Similar to the stomach, we found an about two-fold excess risk for cancer of the colon and rectum (Table 2). All colon cancers were adenocarcinomas. The excess risk appeared unequally distributed along the large bowel; SIR for the right-sided colon was 3.3 (95\% CI = 1.9-5.4), whereas SIR for the left-sided colon (including descending and sigmoid colon) was 1.8 (95\% CI $=0.7-$ 3.6). For rectal cancer, nine cases were adenocarcinomas $(\mathrm{SIR}=1.4,95 \% \mathrm{CI}=0.7-2.6)$. Four were squamous cell carcinomas, and three of them occurred in women. Since the latter category represents anal cancer, they were analysed separately $(\mathrm{SIR}=10.2 ; 95 \% \mathrm{CI}=2.8-26.0)$. We found no increased risk of cancer of the liver and pancreas (Table 2).

\section{Urogenital tract}

The observed numbers of endometrial (corpus uteri) cancers were close to expected and we found a small statistically non-significant 
Table 3 Cancer risk following organ transplantation in Sweden 1970 1997

\begin{tabular}{|c|c|c|c|}
\hline Cancer site (ICD-7) & $\begin{array}{l}\text { Observed } \\
\text { no. cases }\end{array}$ & SIR & $95 \% \mathrm{Cl}$ \\
\hline \multicolumn{4}{|l|}{ Non-kidney transplants SIR for selected sites } \\
\hline Lip (140) & 1 & 24.8 & $0.6-138.6$ \\
\hline Stomach (15|) & 3 & 12.0 & $2.4-35.0$ \\
\hline Colon (153) & 0 & 0 & $0.0-5.8$ \\
\hline Rectal (154) & 2 & 4.5 & $0.5-16.2$ \\
\hline Kidney (I80) & 0 & 0 & $0.0-11.2$ \\
\hline Nonmelanoma skin cancer (191) & $\mid 1$ & 34.0 & $17.0-60.6$ \\
\hline Non-Hodgkin's lymphoma (200, 204, 204.I) & 18 & 37.3 & $22.1-59.1$ \\
\hline All cancers & 53 & 4.9 & $3.7-6.4$ \\
\hline \multicolumn{4}{|l|}{ Kidney transplants SIR for selected sites } \\
\hline Lip (140) & 39 & 54.8 & $39.0-74.9$ \\
\hline Stomach (|5|) & 9 & 1.8 & $0.8-3.4$ \\
\hline Colon (153) & 25 & 2.4 & $1.5-3.5$ \\
\hline Rectal (154) & 12 & 1.7 & $0.9-3.0$ \\
\hline Kidney (180) & 28 & 5.2 & $3.4-7.5$ \\
\hline Nonmelanoma skin cancer (191) & 267 & 57.7 & $51.0-65.1$ \\
\hline Non-Hodgkin's lymphoma (200, 204, 204.I) & 27 & 3.8 & $2.5-5.6$ \\
\hline All cancers & 639 & 3.9 & $3.6-4.2$ \\
\hline
\end{tabular}

Observed number of cases, SIR (SIR) and $95 \%$ confidence intervals (Cl) by cancer site, type and transplanted organ

excess of cancers of the cervix and the ovary. Moreover, the incidence of carcinoma in situ of the cervix was increased only marginally. In contrast, risk for malignancies in the vulva and vagina were markedly increased (Table 2). Of these cases, nine were vulva $(\mathrm{SIR}=26.2 ; 95 \% \mathrm{CI}=12.0-49.8)$ and two were vaginal cancers $(\mathrm{SIR}=16.4 ; 95 \% \mathrm{CI}=2.0-59.3)$.

There was an almost five-fold increased risk of kidney cancer subsequent to organ transplantation. Of these, 19 originated in the renal parenchyma $(\mathrm{SIR}=4.1 ; 95 \% \mathrm{CI}=2.5-6.4)$, whereas six were of pelvic origin ( $\mathrm{SIR}=10.5 ; 95 \% \mathrm{CI}=3.9-22.9)$. An over two-fold statistically significant risk of bladder cancer was revealed; only one of 20 cases was localised in the urethra, whereas the rest occurred in the bladder or at multiple sites. Of the cases, 17 were of transitional cell origin.

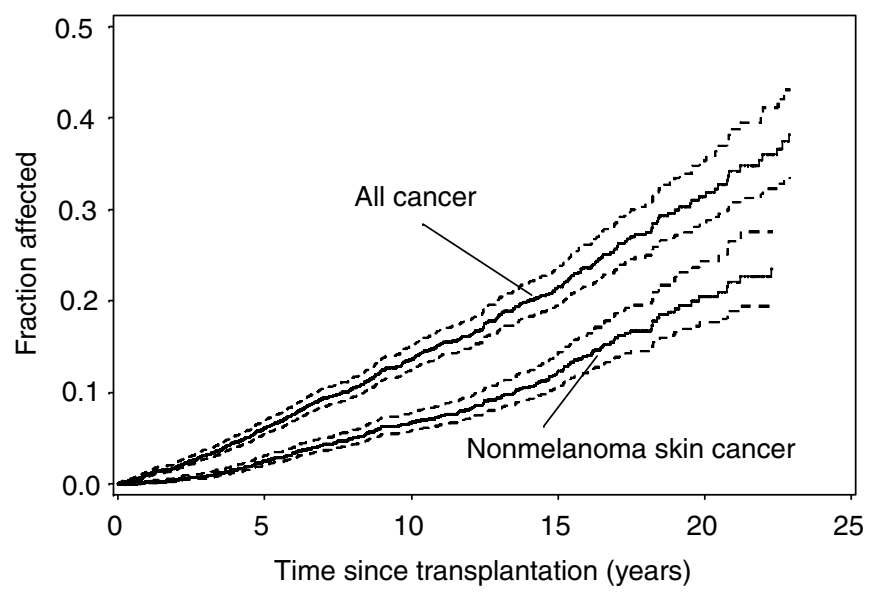

Figure 2 Cumulative risk (solid line) with $95 \% \mathrm{Cl}$ (dotted line) of developing any first malignancy, and nonmelanoma skin cancer, respectively, following transplantation in Sweden, 1970-1997.

\section{Lip and skin cancer}

We found an about 50 -fold excess risk of lip cancer (Table 2). Further multivariate analyses revealed no trend with duration of follow-up, but a significantly higher excess among patients younger than 50 years at transplantation compared to those 50 years or older. Women were at higher risk compared to men, although not significantly. We had limited power to detect any difference in risk related to the type of organ transplanted (Table 4).

A markedly increased risk of nonmelanoma skin cancer was found among the cohort members $(\mathrm{SIR}=56.2,49.8-63.2)$, whereas the excess risk of malignant melanoma was modest and statistically not significant $(\mathrm{SIR}=1.8 ; 95 \%$ CI $1.0-3.0)$. Multivariate analyses revealed that relative risk for nonmelanoma skin cancer remained relatively constant during 1 or more years of follow-up, and was strongly inversely related to age at transplantation. There was no significant difference between men and women, nor between those undergoing kidney transplantation compared with transplantation with other organs (Table 4). The cumulative risk of developing

Table 4 Multivariate analyses of relative risks for all cancers and selected cancer sites following organ transplantation

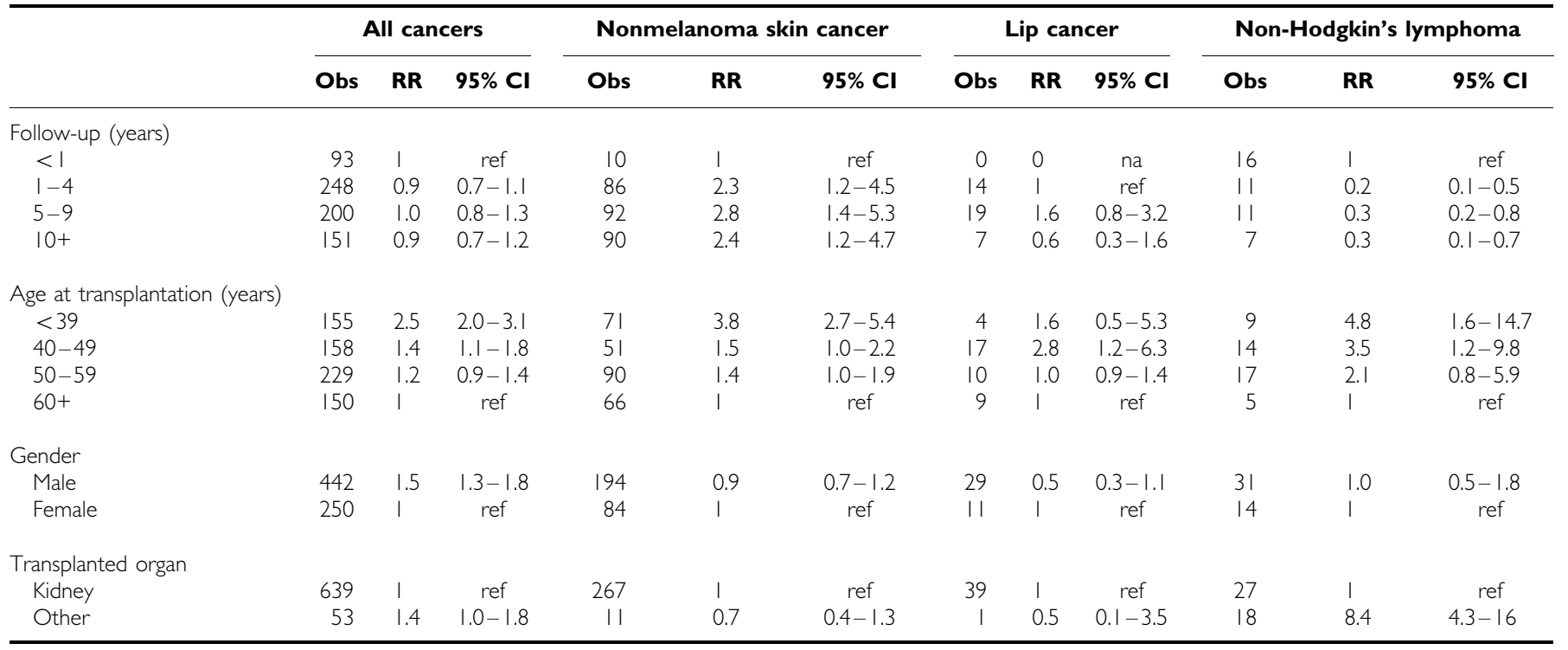

Results shown as relative risks (RRs) and $95 \%$ confidence intervals (Cl) after mutual adjustment for follow-up time, age at transplantation, gender and transplanted organ. 
nonmelanoma skin cancer was $6.7 \%(95 \% \mathrm{CI}=5.7-7.7)$ after 10 years and $20.4 \%(95 \% \mathrm{CI}=17.2-24.6)$ after 20 years (Figure 2$)$.

\section{Haematopoeitic and other malignancies}

There was a six-fold overall excess risk of NHL following organ transplantation (Table 2). Relative risk was drastically increased during the first year following transplantation $(\mathrm{SIR}=19.6 ; 95 \%$ $\mathrm{CI}=11.2-31.9$ ), whereas it remained fairly stable, about four-fold, during all subsequent years. Renal-transplant patients had an increased risk of developing NHL of 9.9 (95\% CI $4.0-20.4)$ during the first year that decreased to 3.2 (95\% CI 1.9-4.9) thereafter, whereas nonrenal transplant patients had an increased risk of 38.0 during the first year (95\% CI $38.0-157.9)$ that decreased to 24.3 (95\% CI 11.1-46.2) thereafter. Multivariate analyses confirmed this pattern and revealed a strong inverse association with age at transplantation, but no association with gender. Moreover, compared with patients who underwent kidney transplantation, those who received other organs were at eight-fold higher risk after adjustment for follow-up time (Table 4). There was also an indication of excess risks of other haematopoeitic malignancies, although the analyses were based on small numbers (Table 2).

We found an increased risk of lung cancer ( $\mathrm{SIR}=1.7 ; 95 \%$ $\mathrm{CI}=1.1-2.5)$. Risk for thyroid cancer was increased four-fold (Table 2) and that for other endocrine tumours was increased eight-fold (data not shown). However, a further analysis of the endocrine group revealed that 31 of the 32 cases were confined to the parathyroid adenomas, presumably reflecting the established association between chronic renal failure and hyperparathyroidism (Gokal, 1988).

\section{DISCUSSION}

Although cancer risk following organ transplantation has been analysed in several prospective studies, only few of them were population based with long-term follow-up (Hoover and Fraumeni, 1973; Kinlen et al, 1979; Birkeland et al, 1995, 2000; Hoshida et al, 1997; Kyllonen et al, 2000; Lindelof et al, 2000), and except for one of the studies (Lindelof et al, 2000), none of them included patients with another transplanted organ than a kidney. While components of our study have been included in earlier analyses (Birkeland et al, 1995) and chiefly in a publication focused on skin cancer (Lindelof et al, 2000), the cohort has now been expanded and the follow-up time added. This expansion has entailed the largest population-based study so far allowing more precise quantification of risk and also separate analyses of several anatomic and histopathologic subtypes. We also had the possibility at comparing cancer risk following transplantation of a kidney with that of other organs, and to analyse effectively duration of follow-up, age at transplantation and gender as determinants of cancer risk.

Our study confirmed a four-fold overall risk of cancer following organ transplantation and further indicated that this excess risk remains seemingly stable during longer follow-up. Moreover, we confirmed a significantly higher overall risk among patients transplanted at young age, among men compared with women, and following transplantation of organs other than a kidney (Kinlen, 1992; Penn, 2000). For specific cancer sites, the excess risk was most notable for nonmelanoma skin cancer, lip cancer and NHL, which is in accordance with other investigators (Hoover and Fraumeni, 1973; Kinlen et al, 1979; Blohme and Brynger, 1985; Barr et al, 1989; Kinlen, 1992; Opelz and Heneerson, 1993; Birkeland et al, 1995, 2000; Bouwes Bavinck et al, 1997; Hoshida et al, 1997; Kyllonen et al, 2000; Lindelof et al, 2000; Penn, 2000). In the study by Lindelöf et al (2000), the SIRs included all incident cancers, whereas in our study, we only counted the first cancer. This possibly explains the differences in RR magnitudes between these two studies. Novel findings in our study include the substantial excess risk for cancer of the tongue, anus, vulva and vagina, but no convincing excess risk for in situ or invasive cancer of the cervix as reported previously (Porreco et al, 1975; Sillman et al, 1984), and evidence of a higher risk for kidney cancer with pelvic origin than that of parenchymal origin.

While we consider the internal validity of our study to be high, several limitations should be emphasised. Since we were unable to scrutinise almost 6000 medical records individually, we had to rely on information from the In-patient Discharge Register. It is difficult to reconstruct from this register accurately the course of events following an organ transplantation which may include explantation as well as one or several replantations. Most likely, neither failure to censor follow-up in some patients because they were neither transplanted nor immunosuppressed entails some underestimation of excess risks. Notwithstanding the relatively large size of the study, we had insufficient power to analyse several rare malignancies and to confirm moderate excess risks. Moreover, we could not effectively adjust for potential confounding because we had neither data on life-style factors among organ-transplanted patients nor among the general Swedish population that generated the expected cancer incidence rates. About 30\% of transplanted patients have diabetes (The Swedish Registry of Vrenic Care 2000), a disease associated with an excess risk of several malignancies (Adami et al, 1991). Diabetes is unlikely, however, to explain our pattern of findings because this disease is associated most strongly with cancer of the liver (Lagiou et al, 2000) and endometrium (Weiderpass et al, 2000), two sites for which we observed no excess risk following transplantation. Long-term dialysis preceding kidney transplantation is another conceivable confounder, although studies of cancer risk in such patients have been inconclusive (Kantor et al, 1987; Fairley et al, 1994; Maisonneuve et al, 1999; Birkeland et al, 2000). Lastly, many of the excess risks we observed were substantially higher than those generally found in relation to established risk factors for the respective malignancies. Hence, confounding may indeed be a limited concern and most of the risks we observed might be attributable to the organ transplantation and subsequent immunosuppressive therapy.

Our study was not designed to elucidate the numerous mechanisms that have been invoked to explain the excess cancer risk following organ transplantation (Penn, 1991). Among these, immune modulation is the most obvious, and likely the most important. Prevalent infection with several potentially oncogenic viruses and bacteria, such as EBV, human papilloma virus (HPV), HHV-8, HTLV-1, HIV and Helicobacter pylori, might become activated by impaired immune function (Goedert, 2000). As several of these, notably HHV-8, HTLV-1 and HIV, are rare in the Swedish population, measurable effects on cancer risk appear unlikely. Although EBV may account for the substantial excess risk of NHL - appearing with a short latency and being most marked after organ transplantation other than the kidney - the possible role of other viruses yet to be detected is presently unknown. Although activation of $H$. pylori might explain the excess risk of stomach cancer, this bacterium appears most strongly associated with distal stomach cancer (Huang et al, 1998) while we, if anything found higher excess risk for proximal cancers.

Most enigmatic were our findings with regard to cancers associated with HPV. Unknown HPV subtypes are hypothesised to play a role in the aetiology of nonmelanoma skin cancer (Blohme and Brynger, 1985; Barr et al, 1989; Bouwes Bavinck et al, 1997) and defined oncogenic types are clearly causally related to cancer of the cervix (IARC, 1995), anus (Frisch et al, 1997), vulva and vagina (Blohme and Brynger, 1985; Alloub et al, 1989). Although controversial, HPV has also been proposed as a risk factor for oesophageal cancer (Galloway and Daling, 1996) as well as for head and neck cancers (Mork et al, 2001). However, if altered immune function entails activation of HPV infection and thereby increased viral load, an excess risk of malignancies of the cervix should be 
expected (Ylitalo et al, 2000), but no convincing excess was observed. This leads us to hypothesise that anatomic differences in immunologic control of HPV-harbouring target cells explains the spectacular differences in risk for HPV-associated malignancies. The substantial excess risk for numerous malignancies without any established or suspected infectious aetiology further suggests that the mechanisms by which organ transplantation increases cancer risk may be more complicated than an infectious-driven malignant transformation. This finding seems to challenge the established concept that most tumours are nonimmunogenic. Moreover, recent experimental data from immunodeficient double-knockout mice show increased incidence of several spontaneous tumour types (Shankaran et al, 2001).

In conclusion, we provide further evidence of an association between organ replacement and the development of a number of different malignancies. These results indicate the need for further investigation as the numbers of transplant recipients increase and their life expectancy improves. A better understanding of factors that determine cancer risk might serve several purposes. First, an immunosuppressive regimen could be designed to minimise cancer risk whenever possible. Second, a better quantification of cancer risks might facilitate early diagnoses and thereby potentially improve prognosis. Lastly, detailed studies of cancer following organ transplantation might advance our understanding of the carcinogenic process and the role of immune surveillance for several cancer sites and types.

\section{ACKNOWLEDGEMENT}

This work was supported by a grant from the Swedish Cancer Society.

\section{REFERENCES}

Adami HO, McLaughlin J, Ekbom A, Berne C, Silverman D, Hacker D, Persson I (1991) Cancer risk in patients with diabetes mellitus. Cancer Causes Control 2: $307-314$

Alloub MI, Barr BB, McLaren KM, Smith IW, Bunney MH, Smart GE (1989) Human papillomavirus infection and cervical intraepithelial neoplasia in women with renal allografts. BMJ 298: $153-156$

Barr BB, Benton EC, McLaren K, Bunney MH, Smith IW, Blessing K, Hunter JA (1989) Human papilloma virus infection and skin cancer in renal allograft recipients. Lancet 1: 124-129

Birkeland SA, Lokkegaard H, Storm HH (2000) Cancer risk in patients on dialysis and after renal transplantation. Lancet 355: $1886-1887$

Birkeland SA, Storm HH, Lamm LU, Barlow L, Blohme I, Forsberg B, Eklund B, Fjeldborg O, Friedberg M, Frodin L, et al (1995) Cancer risk after renal transplantation in the Nordic countries, 1964-1986. Int J Cancer 60: $183-189$

Blohme I, Brynger H (1985) Malignant disease in renal transplant patients. Transplantation 39: $23-25$

Bouwes Bavinck JN, Claas FH, Hardie DR, Green A, Vermeer BJ, Hardie IR (1997) Relation between HLA antigens and skin cancer in renal transplant recipients in Queensland, Australia. J Invest Dermatol 108: $708-711$

Breslow NE, Day NE (1987) Statistical methods in cancer research. Volume 2 The design and analysis of cohort studies. IARC Sci Publ 1-406

Fairley CK, Sheil AG, McNeil JJ, Ugoni AM, Disney AP, Giles GG, Amiss N (1994) The risk of ano-genital malignancies in dialysis and transplant patients. Clin Nephrol 41: $101-105$

Frisch M, Glimelius B, van den Brule AJ, Wohlfahrt J, Meijer CJ, Walboomers JM, Goldman S, Svensson C, Adami HO, Melbye M (1997) Sexually transmitted infection as a cause of anal cancer. $N$ Engl J Med 337: $1350-1358$

Galloway DA, Daling JR (1996) Is the evidence implicating human papillomavirus type 16 in esophageal cancer hard to swallow? J Nat Cancer Inst 88: $1421-1423$

Goedert J (2000), In: Infectious Causes of Cancer. Targets For Intervention. Press H (ed). New Jersey

Gokal E (1988) Renal oestodystrophy and aluminium bone disease in CAPD patients. Clin Nephrol (Suppl 30): 64-67

Harris NL, Jaffe ES, Stein H, Banks PM, Chan JK, Cleary ML, Delsol G, De Wolf-Peeters C, Falini B, Gatter KC (1994) A revised EuropeanAmerican classification of lymphoid neoplasms: a proposal from the International Lymphoma Study Group. Blood 84: 1361-1392

Hoshida Y, Tsukuma H, Yasunaga Y, Xu N, Fujita MQ, Satoh T, Ichikawa Y, Kurihara K, Imanishi M, Matsuno T, Aozasa K (1997) Cancer risk after renal transplantation in Japan. Int J Cancer 71: 517-520

Hoover R, Fraumeni Jr JF (1973) Risk of cancer in renal-transplant recipients. Lancet 2: 5-7

Huang JQ, Sridhar S, Chen Y, Hunt RH (1998) Meta-analysis of the relationship between Helicobacter pylori seropositivity and gastric cancer. Gastroenterology 114: 1169-1179
IARC Monographs on the Evaluation of Carcinogenic Risks to Humans, Vol 64. Human Papillomaviruses. (1995) In Lyon: International Agency for Research on Cancer

Kantor AF, Hoover RN, Kinlen LJ, McMullan MR, Fraumenti Jr JF (1987) Cancer in patients receiving long-term dialysis treatment. Am J Epidemiol 126: $370-376$

Kinlen LJ (1992) Immunosuppression and cancer. IARC Sci Publ 116: $237-253$

Kinlen LJ, Sheil AG, Peto J, Doll R (1979) Collaborative United KingdomAustralasian study of cancer in patients treated with immunosuppressive drugs. Br Med J 2: $1461-1466$

Kyllonen L, Salmela K, Pukkala E (2000) Cancer incidence in a kidneytransplanted population. Transpl Int 13(Suppl 1): S394-S398

Lagiou P, Kuper H, Stuver SO, Tzonou A, Trichopoulos D, Adami HO (2000) Role of diabetes mellitus in the etiology of hepatocellular carcinoma. J Natl Cancer Inst 92: 1096-1099

Lindelof B, Sigurgeirsson B, Gabel H, Stern RS (2000) Incidence of skin cancer in 5356 patients following organ transplantation. $\mathrm{Br}$ J Dermatol 143: $513-519$

Maisonneuve P, Agodoa L, Gellert R, Stewart JH, Buccianti G, Lowenfels AB, Wolfe RA, Jones E, Disney AP, Briggs D, McCredie M, Boyle P (1999) Cancer in patients on dialysis for end-stage renal disease: an international collaborative study. Lancet 354: $93-99$

Mork J, Lie AK, Glattre E, Hallmans G, Jellum E, Koskela P, Moller B, Pukkala E, Schiller JT, Youngman L, Lehtinen M, Dillner J (2001) Human papillomavirus infection as a risk factor for squamous-cell carcinoma of the head and neck. N Engl J Med 344: 1125-1131

Nilsson AC, Spetz CL, Carsjo K, Nightingale R, Smedby B (1994) Reliability of the hospital registry. The diagnostic data are better than their reputation. Lakartidningen 91: 598,603-605

Nyren O, McLaughlin JK, Gridley G, Ekbom A, Johnell O, Fraumeni Jr JF, Adami HO (1995) Cancer risk after hip replacement with metal implants: a population-based cohort study in Sweden. J Natl Cancer Inst 87: $28-33$

Opelz G, Henderson R (1993) Incidence of non-Hodgkin lymphoma in kidney and heart transplant recipients. Lancet 342: 1514-1516

Penn I (1991) The changing pattern of posttransplant malignancies. Transplant Proc 23: 1101-1103

Penn I (1993) Tumors after renal and cardiac transplantation. Hematol Oncol Clin North Am 7: 431-445

Penn I (2000) Cancers in renal transplant recipients. Adv Ren Replace Ther 7: $147-156$

Porreco R, Penn I, Droegemueller W, Greer B, Makowski E (1975) Gynecologic malignancies in immunosuppressed organ homograft recipients. Obstet Gynecol 45: 359-364

Shankaran V, Ikeda H, Bruce AT, White JM, Swanson PE, Old LJ, Schreiber RD (2001) IFNgamma and lymphocytes prevent primary tumour development and shape tumour immunogenicity. Nature 410: 1107-1111

Sillman F, Stanek A, Sedlis A, Rosenthal J, Lanks KW, Buchhagen D, Nicastri A, Boyce J (1984) The relationship between human papilloma- 
virus and lower genital intraepithelial neoplasia in immunosuppressed women. Am J Obstet Gynecol 150: 300-308

The Swedish Cancer Registry (2001) Cancer Incidence in Sweden, (1998). Stockholm: National Board of Health Welfare

The Swedish Registry of Uremic Care (2000) Publication no 7

Weiderpass E, Persson I, Adami HO, Magnusson C, Lindgren A, Baron JA (2000) Body size in different periods of life, diabetes mellitus, hypertension, and risk of postmenopausal endometrial cancer (Sweden). Cancer Causes Control 11: 185-192

Ylitalo N, Sorensen P, Josefsson AM, Magnusson PK, Andersen PK, Ponten J, Adami HO, Gyllensten UB, Melbye M (2000) Consistent high viral load of human papillomavirus 16 and risk of cervical carcinoma in situ: a nested case-control study. Lancet 355: $2194-2198$ 